\title{
Location of Civil Engineering Infrastructures in Relation to River Areas
}

José M de UREÑA*

School of Civil Engineering, University of Castilla la Mancha. Spain

*Corresponding author: José M de UREÑA, Emeritus Professor of City and Regional Planning, School of Civil Engineering, University of Castilla la Mancha, Spain.

Received Date: April 19, 2021

Published Date: April 29, 2021

\section{Abstract}

The article describes the dynamics and roles of the different fluvial areas. It pays particular attention at describing the new concept of area of fluvial freedom and at the role of the riparian corridor so that rivers can maintain their role of motorway of life. Taking these into consideration, the article explores the degree of interference of different ways of locating bridges and roads in relation to rivers and the reasons for these infrastructures being places close to them.

Keywords: Fluvial dynamics; River areas; Bridges; Roads; Civil engineering; Riparian corridor

\section{Introduction}

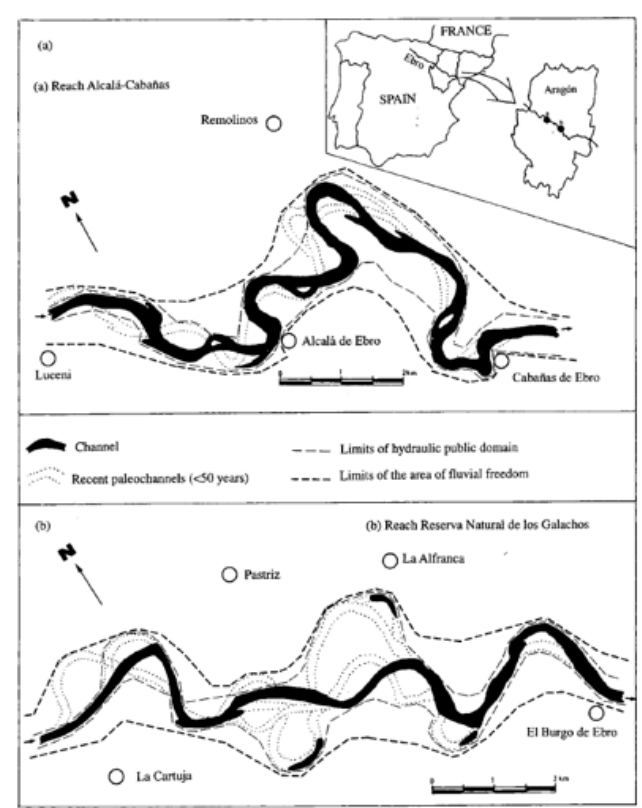

Source: Ollero [4,5] and Ureña \& Ollero [2]

Figure 1: Ebro river, channel dynamics in two middle course reaches: present and past river channels. 
Fluvial/river areas and infrastructures (roads, bridges, dams, cities, etc.) present different and even contradictory physical characteristics. In general, fluvial areas can be presented as complex, flexible, and changing, while infrastructures could be described as simple, rigid, and permanent. These differences/ contradictions generate conflicts when locating infrastructures nearby fluvial/river areas. There have been several descriptions of fluvial areas, including the most traditional one based on the riverbed and its lateral adjacent ones, the riparian corridor, and the floodplain. Nevertheless, most recent descriptions put the emphasis on what is call the "area of fluvial freedom" [1-3]. The riverbed is not permanent but change's locations through the processes of erosion, sedimentation, and flooding. Changing timing is not fixed and short but depends on the geologic, topographic and climate characteristics of its basin. Nevertheless, riverbed changes do not necessarily happen along very long periods of time (geologic time periods) but are observable along human live periods or a few centuries and are perceived in maps (see Figures $1 \& 2$, and Ureña \& Ollero [1,2]). Thus, using riverbed as the basic river element for its description/determination is not a good decision since its location is not permanent. Trying to combine river areas with infrastructures requires the use of more permanent fluvial territorial areas (Figure 1).

The riverbed moves inside a more permanent band of territory that has been called the "area of fluvial freedom" (espace de liberté fluviale in French or espacio de libertad fluvial in Spanish) (see Figures 1,2 \& 3). This area of fluvial freedom includes not all the periodical river changes, since flooding is another of these changes, but it definitively includes the most relevant ecological areas. The external geographical limits of the area of fluvial freedom is a much more permanent one and can be efficiently used as the basis for river determination (Figure 2 ).

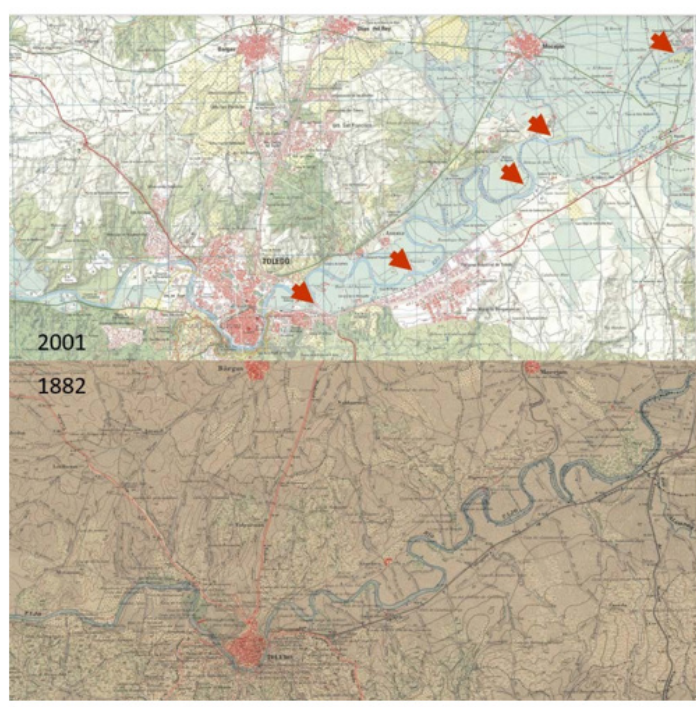

Source: Author and Instituto Geográfico Nacional

Figure 2: Changes between in 1882 and 2001 of the Tagus Riverbed upstream of Toledo.

A river is defined in dictionaries as "a large natural stream of water flowing in a channel to the sea, a lake, or another river". But, in my opinion, this definition is not the best one to debate the relation between infrastructures locations and rivers. I propose considering rivers "motorways of life" where life development takes place mainly along the area of fluvial freedom, and particularly along a part of it which is the riparian corridor. This riparian band, which as well as the riverbed are not permanent, but periodically change, intermixes water, land and air, it is in fact the bank of the river, but not as a line that separates land and water, but rather as an intensely vegetated and shaded territorial band, very irregular, with inlets and outlets of water and land, that changes frequently, that interconnects the water, land and air ecosystems; and all these characteristics are crucial for fauna reproduction. The riparian band includes also important bank irregularities (produced by roots and by inlets and outlets) which play another crucial role, that of diminishing the water velocity during floods and thus allowing for young fish and amphibians survival. An irregular, wide and vegetated riparian corridor is a key element for the river being a "motorway of life". And it is a motorway of life since water, land and air fauna and flora use the river for their natural lifecycle movements (reproduction, breading, feeding, etc..). The riparian corridor is thus very flexible and changing, the life cycle of its most characteristic vegetation, the salicaceae family, has been autogenerated to perfectly coincide with the other fluvial cycles (erosion, sedimentation, flooding, etc.). This area of fluvial freedom is, in general, the lowermost part of the river basin. Figure 3 shows a synthetic graphic model of a river reach and in this model the riverbed and the riparian corridor are qualified as being "transitorial" (non-permanent) elements (Figure 3). 


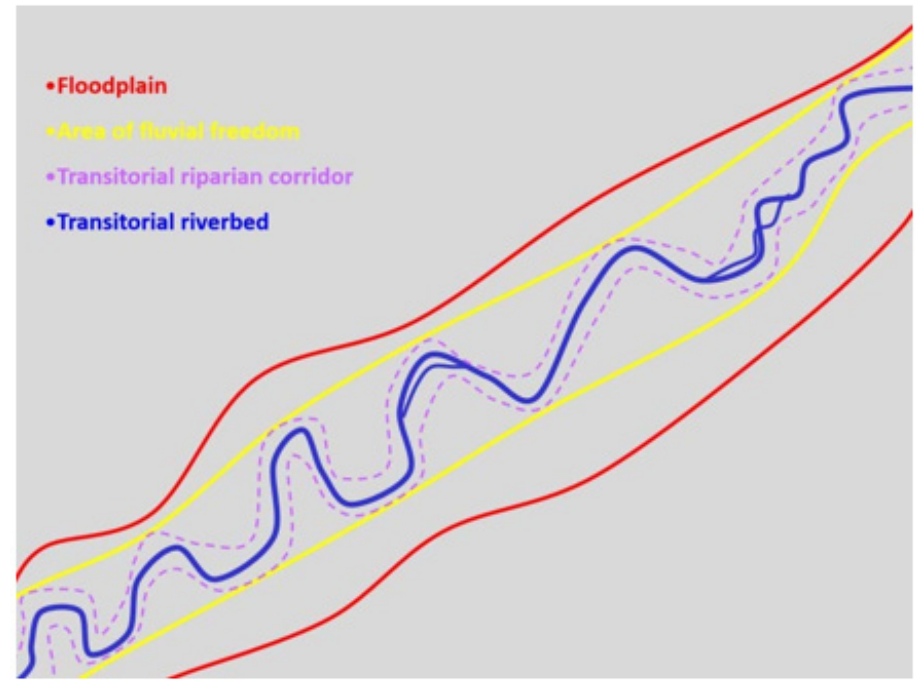

Source:Author

Figure 3: Characteristic fluvial areas.

Outside this band of fluvial freedom, the river is much more permanent in its location, but still the land occupied by water changes through periodical flooding. This flooding areas are used in different degrees and time periods by different intensity floods (return periods of 10,40,100, 200,500, etc. years), and its main role is to store water (and sediments) so that flooding does not increases downstream. The risks of flooding for human uses are normally calculated as the product of water speed and depth. The general form of these flooding areas is of gradual slopes and their ecological relevance is less important than the riparian band's one. Mapping riverbeds has taken place for centuries, calculating and mapping floodplains of different return periods is becoming common and occasionally compulsory for some development projects (i.e., land use plans or infrastructure design projects), but areas of fluvial freedom are very rarely mapped so far. While rivers are changing, flexible and complex territorial elements, infrastructures are built to tend to always ensure a permanent use and thus require a strong and stable built-up form. Changing processes, such as erosion or locational movements, are no-tolerable ones on the contrary infrastructure foundations are generally designed/built to avoid them. Often decisions have been taken for infrastructures to occupy river/fluvial areas due to scarcity or price of alternative land and due, many times, to the continuous character or relatively flat land besides and along riverbeds.

\section{Discussion}

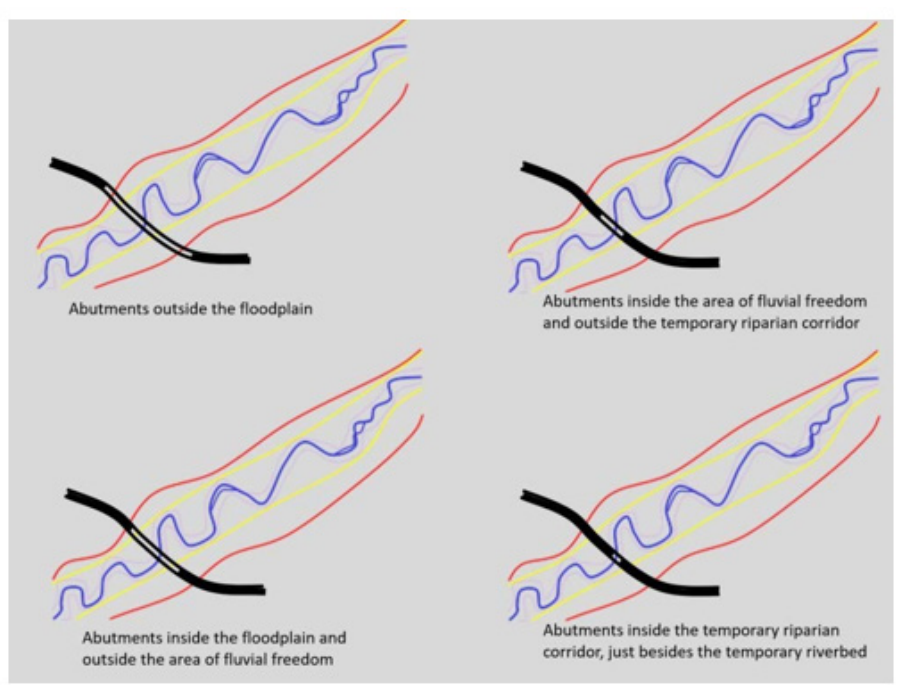

Source: Author

Figure 4: Options for locating bridge abutments in relation to river areas. 
Considering the contradictory character of fluvial areas and infrastructures, briefly described in the previous section, in this section we are going to discuss how to best locate bridges and roads in relation these fluvial areas, so that rivers maintain their "motorway of life" role. Present official government design manuals of bridges and roads pay very little attention to location criteria in relation to rivers, barely nothing more than a few risk recommendations, see for instance the California, Colorado or Spanish manuals2. The chapter on environmental requirements of the Spanish Design Manual only indicates that "The presence of water courses likely to cause undermining may make it advisable not to have piers in their channels, with the consequent limitation of possible types by increasing the spans length." A river bridge is a fixed material element that crosses the fluvial corridor, this is to say the floodplain and the area of fluvial freedom. The bridge will have a starting and a finishing point, the abutments, the contact between the bridge and the road embankments before and after the bridge, and it may have some piers to support the bridge deck. The first question is where abutments should be located in relation to rivers. There are four possibilities (see Figure 4):

1. Abutments outside the floodplain. This is as if the bridge did not interfere with the river at all.

2. Abutments inside the floodplain and outside the area of fluvial freedom. This location interferes with the floodplain but does not interfere with riverbed and riparian corridor integrity and movement. In summary, the bridge will only increase slightly flooding upstream.

3. Abutments inside the area of fluvial freedom and outside the temporary riparian corridor. This option starts to have greater interferences with the river. First, the bridge starts resembling a "dam with a central big spillway" and flooding upstream will increase to a certain degree. And second, it produces a new fixed/permanent river point, diminishing/ preventing the movements of riverbed and riparian corridor This movement prevention may mean in the future that abutments could suppress the riparian corridor for a short length.

4. Abutments inside the temporary riparian corridor, just besides the temporary riverbed. This option has very important interferences with the river. First, it increases both interferences of the previous option, with substantially greater flooding upstream, since embankments play increasingly more the role of a dam. Second, the riparian corridor is not only fixed, but possibly discontinued in its vegetation and its inlets/outlets of water and land along a certain river length, thus breaking its ecological continuity and breading roles.

The second question is where piers should be located and more specifically how thick can they be. The thinner the piers the lesser impact on the river natural dynamics. Thick piers interfere in similar ways as abutments. Thick piers by the temporary riparian corridor interfere importantly with its ecological role, in similar ways as abutments. The main difference between abutments and piers is that riverbed and riparian corridor movements are normally not affected unless they are very thick. A crucial figure is the length between abutments that is left free from piers for eater flow. Roman bridges for instance my only have $40 \%$ or even less free span between abutments since piers are very thick. But why is that bridges are normally designed reducing the separation between abutments (options two, three and four). Two are the reasons for trying to diminish the length between abutments (total span of the bridge) prolonging the road embankments, and for increasing the number of piers. The first reason is that the cost of a bridge is, in general terms, proportional to the square of its total span and of each span between piers, thus the tendency will be to shorten the length of the bridge and to increase the number of piers. Nevertheless, piers have an additional cost in their foundation, which may modify the previous argument. The second reason, which often happens, is that road building will be cheaper minimizing earthwork cut (excavation) and fill (embankment) volumes such that the percent difference between cut and fill is small and such that the distance this earth has to be transported is minimized. When earth cut needs to be abundant, this economic criterion often results in increasing road embankments besides a bridge and reducing its total span (reducing distances between abutments). An example of a recently built bridge is the Third Millennium Bridge, designed by Juan José Arenas, civil engineer and professor of bridges at the School of Civil Engineering of the University of Cantabria, on the occasion of the 2008 Water World Expo at Zaragoza and located at the edge of the city (see Figure 5).

The river Ebro's area of fluvial freedom and floodplain besides Zaragoza are between 1,5 and $3.5 \mathrm{~km}$ wide (see Figure 1), while the separation between bridge abutments is only 330 metres (see Figure 5), only between one third and tenth of the natural floodplain. Thus, the elevated embankments at both sides of the bridge are generating a "dam" effect which will increase flooding upstream and will increase considerably the water speed at the bridge river stretch during floods, making it difficult for fish fry to survive. The bridge has three piers, all of them very rigid (see Figure 5). Two at a small distance from each riverbed, wider than the bridge deck, creating two rigid riverbanks, and allowing for vegetation, but not for inlets/outlets of land and water at each riverbed. It also has a massive third pier at a greater distance from the north side riverbed, which interferes only with the floodplain. In total, the percentage of total bridge span occupied by piers is around one sixth which means a small additional effect on increasing flooding upstream and water flow speed at the bridge section (Figure 5).

Roads may have a greater interference with rivers than bridges, since bridges only impact rivers along a short stretch, while roads may be located besides rivers along much longer stretches. Considering roads not crossing rivers (since this case has already been discussed by bridges), they consist of a continuous rigid band 
of land with limited slopes and curve radius (the greater the design speed the smaller the slopes and the greater the curves radius) and with a minimum width; a width which is increased in sections with embankments and cuts, with greater number of lanes and with intersections. Within the interferences of roads on rivers that will be debated we will not include the fauna movement barrier effect for crossing roads. This interference must be dealt not only near rivers, but everywhere. Nevertheless, near rivers this crossing road barrier effect has greater importance since access to water is crucial for fauna. Similarly, to bridge abutments, location options of roads in relation to fluvial/river areas could be synthesised in four options (see Figure 6):

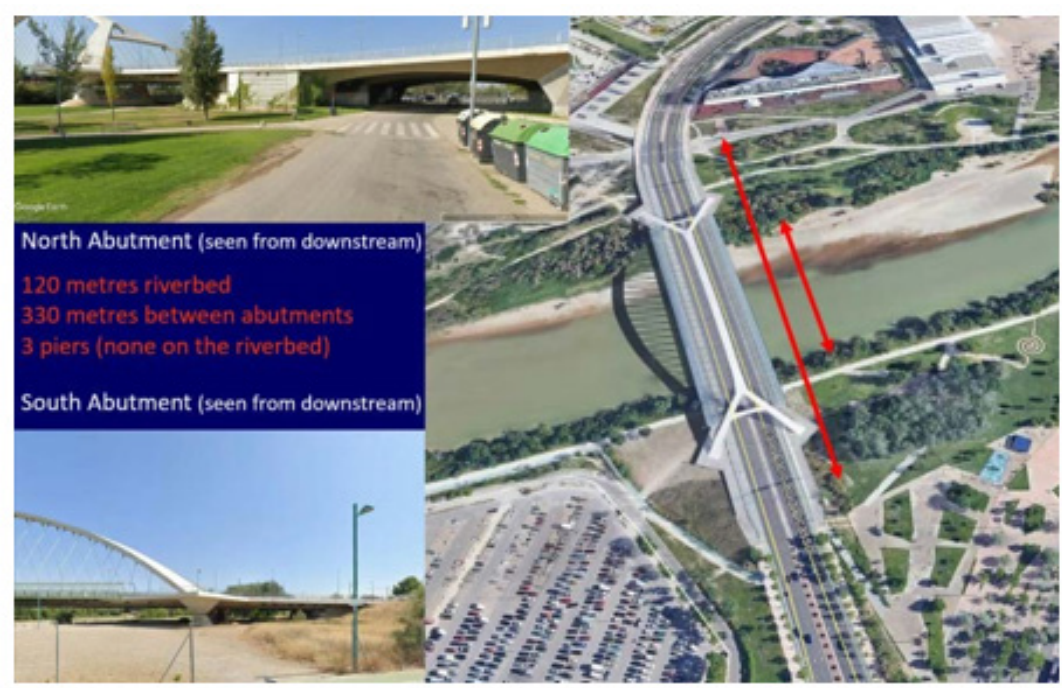

Source: Google Earth

Figure 5: The Third Millennium Bridge and the river Ebro.

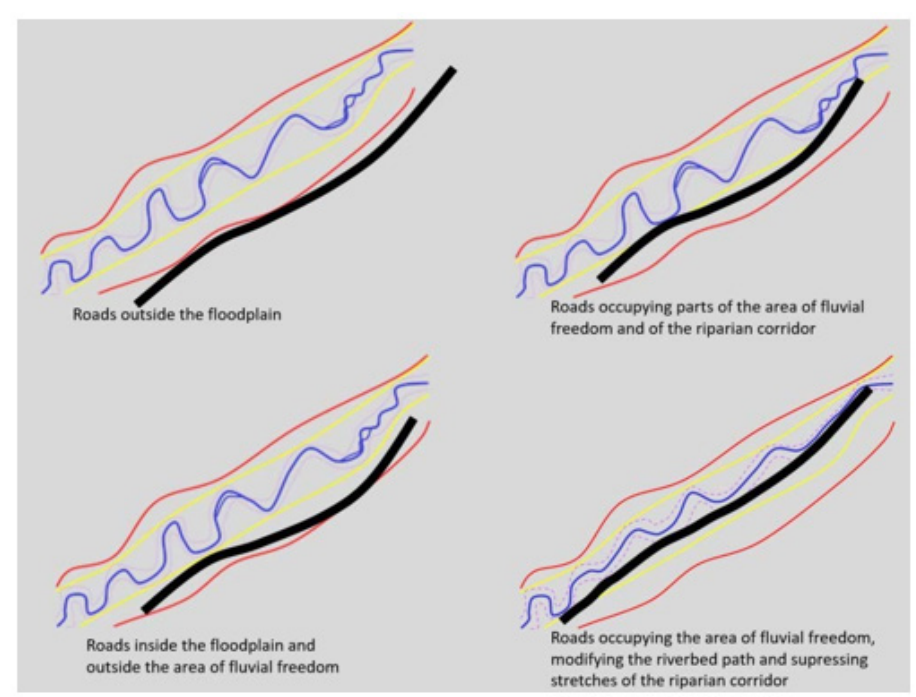

Source: Author

Figure 6: Options for locating roads in relation to river areas.

1. Roads outside the floodplain. This is as if the road did not interfere with the river almost at all, although it will modify runoff from slopes into the river.

2. Roads inside the floodplain and outside the area of fluvial freedom is very similar to the previous option, although the road will additionally diminish to a certain degree the floodplain area (since it will normally raise the level of its path area) and produce a certain increase of flooding downstream.

3. Roads occupying parts of the area of fluvial freedom and of the riparian corridor. This option starts to interfere importantly with the natural river dynamics. First, it will reduce the capacity of the riverbed to move (change riverbed location) since the road infrastructure will be rigid and permanent. Second, it will reduce the fauna breeding capacity by suppressing the riparian 
corridor along a certain river stretch. The two main variables that define the relevance of this last interference are length and frequency of riparian corridor suppression and continuity of riparian corridor along the other riverbank.

4. Roads occupying the area of fluvial freedom, modifying the riverbed path and supressing stretches of the riparian corridor. This option produces the greatest interferences. To make room for the road, it not only occupies parts of the area of fluvial freedom, but the riverbed is transformed, normally diminishing its complexity, and reducing its length. This will not only supress more radically parts of the riparian corridor (see previous option) but increases the riverbed slope (equal hight differences along less distance) and thus increases water speed and erosion downstream (Figure 6).

Why is that roads are many times designed/built occupying parts of rivers? The answer is twofold. First, because topography is smoother besides rivers, since they have eroded the land, and most importantly, they have sedimented land generating relatively flat areas, quite appropriate for locating roads with greater design speed (lesser slopes and greater curve radius). Second, because riverbeds and adjacent lands include publicly owned lands, thus is "much cheaper" to occupy these lands than to buy privately owned ones. Along history, humans have constantly occupied river areas as a result of a misunderstanding of their key role in life breading. Public land may not have to be paid when occupied for roads, but the overall cost of deteriorating rivers live breading functions may be much greater than the cost of acquiring private land. An example of a recently built road besides rivers is the M-30 ring motorway at Madrid, built during the 1970's and partially rebuilt during the 2000's (see Figure 7). Its south west part follows the river Manzanares, rebuilt during the 2000's, its eastern part follows the Abroñigal stream and its norther one occupies parts of the Veguila stream.

The Abroñigal and the Veguila streams were converted in sewer pipelines and the motorway built over them. The Manzanares river, already quite diminished in water flow, since much of it is diverted upstream and used for supply purposes, was first flanked by the motorway in the 1970's and during the 200's, through the rebuilding process, flanked by motorway tunnels covered by a park (see Figures 8 \& 9). Three main aspects/changes can be seen on this whole process in the south western part of the M30 Motorway besides the Manzanares river. First, the motorway was built constricting the riverbed and leaving it un accessible for humans (see first images of Figures 8 and 9). The riverbanks were consolidated, and vegetation existed only at the level of the motorway, not at the level of water as riparian vegetation takes place, along a small strip of land with almost no riparian corridor effect. The riverbed was really a series of water ponds maintained by a sequence of small dams. In a sense the river was isolated from intense human use, which may be positive for natural processes, but on the contrary the flow of water and the riparian corridor almost did not exist, which is certainly negative for them (Figures 7,8).

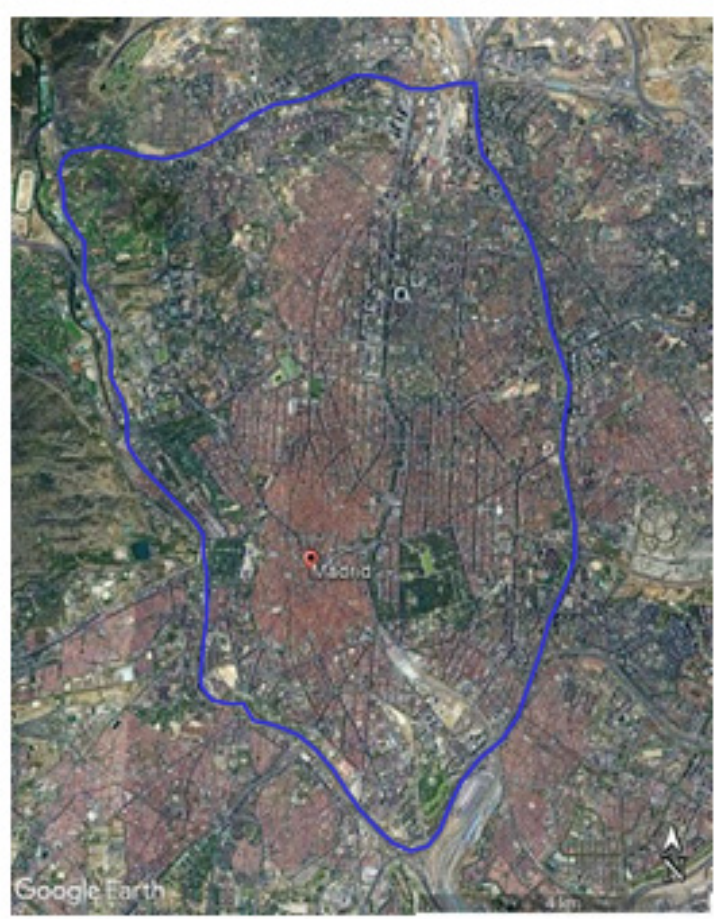

Source: Author and Google earth.

Figure 7: M-30 ring motorway Madrid. 


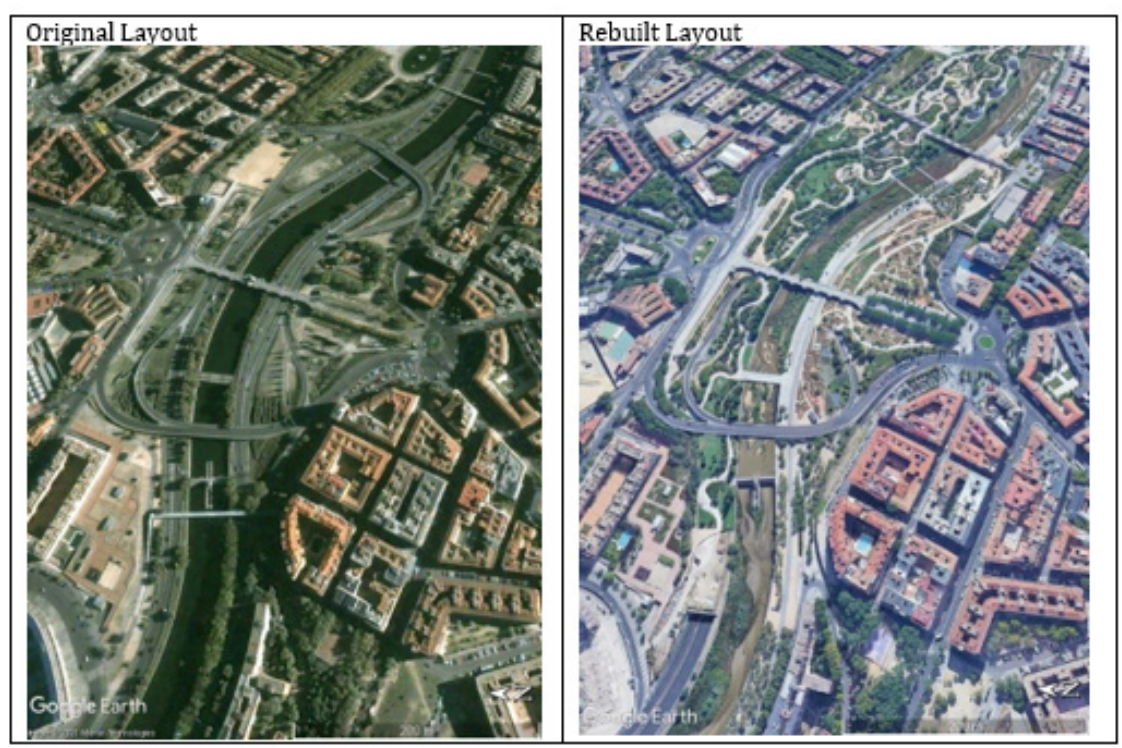

Source: Google earth

Figure 8: Views of the eastern part of the M-30 ring motorway: original layout and rebuilt one.

Second, putting this motorway section underground also resulted in positive and negative interferences with the river. From a material point of view the main consequences are the creation of a continuous park besides the river, the appearance of entrance and exit ramps of the tunnels that impact the park, and the growth in height of the solid riverbank walls, since the level difference between water and park surface was increased to reduce required excavation for the tunnels (see second images of Figures 8 and 9). The park means an increase in vegetation, but it happens even at a further vertical distance than previously from the water, it also means an increase in human use of the area, very positive for the city and its inhabitants, but possibly neutral in relation to the almost inexistent riparian corridor, since human use takes place around 7 meters above water level. The third is not a consequence of the motorway or its rebuilding, but of something independent that started to take place just after the rebuilding process. Water management institutions, pressed by ecologists' organizations, decided to suppress the sequence of dams and maintain a small flow of water (instead of a series of water ponds). This is meaning that a smaller irregular, meandering riverbed is being generated inside the concrete larger one through sediments and these sediments are starting to be vegetated with herbs, but still no trees, and probably so for many years, since tree rooting is difficult in the concrete bed. (see second image of Figure 8 and third image of Figure 9) [4,5].

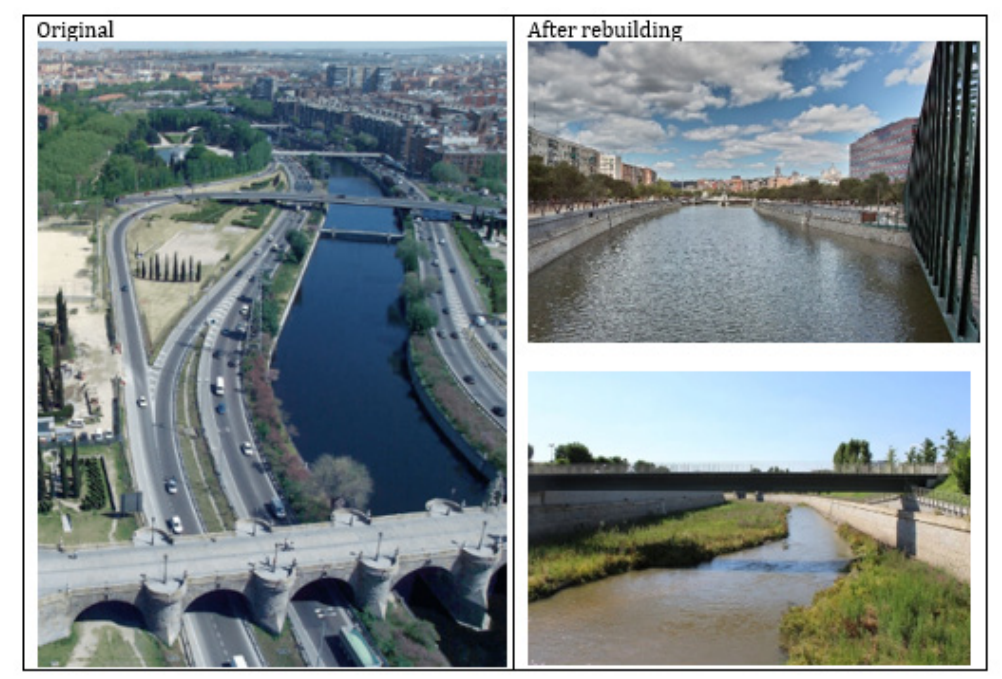

Source: Author

Figure 9: Riverbanks original and after rebuilding layouts. 


\section{Conclusion}

This article is based on a theoretical and experimental research by the author and other colleagues on river natural dynamics. Based on this research the author has deduced several consequences and options for laying out bridges and roads in relation to rivers and shows a few examples. This second part is not well systematized as to be considered a research article. This is why this article is presented as an opinion one. Too often civil engineering infrastructures are laid out on the territory without detailed studies of their ecological consequences. Nevertheless, the growing concern of the limits of natural resources and the need for more sustainable development (engineering) is highlighting new requirements for infrastructure territorial location.

At present our societies are experiencing a change in relation to what we can build besides rivers. During a substantial part of the XX century the strategy consisted in constricting rivers to a limited band of land and reinforced and high and rigid riverbanks, so that outside these riverbanks the river will not move, and flooding will not take place, and thus, anything can be built outside this reinforced river channel, and water flood and erosion/sedimentation should not generate risks on them. Thus, the emphasis was put on physical protection against floods and reduction of river land occupation. After a few decades, the strategy is changing into rivers being able to occupy, permanently and temporary, a greater amount of territory, river adjacent areas with a reduced physical protection against flooding and limiting location of uses/buildings/infrastructures to places where flooding is compatible with them. In summary, our societies are starting to leave more room for rivers to maintain their natural dynamics. The article suggests that rivers are better understood as motorways or bands of life; bands that are very productive ecologically since they combine land, water, and air ecosystems; bands that are very complex and experience location changes, with these complexities being crucial for file breading. This new positive vision of river/fluvial areas is generating a reconsideration about transforming them into simple geometry, permanent and robust infrastructure areas. Even more, there is a social and professional movement for river restauration, seeking re- naturalizing fluvial areas that have previously been impacted by infrastructures, cities, etc.

\section{Acknowledgment}

None.

\section{Conflict of Interest}

No conflict of interest.

\section{References}

1. Ureña JM, Ollero A (2000) Criteria and proposals for the management of river areas, City and Territory. Territorial Studies 126: 689-710.

2. Ureña JM, Ollero A (2001) Fluvial landscapes, catchment administration and land-use planning: experience based on two rivers in Spain, Landscape Research 26(3): 225-243.

3. Kondolf GM (2012) Chapter 18 The Espace de Liberté and Restoration of Fluvial Process: When Can the River Restore Itself and When Must we Intervene? In: Boon PJ, Raven PJ (Eds.) River Conservation and Management, Wiley-Blackwell, Hoboken, New Jersey, USA, pp. 212-225.

4. Ollero A (1995) Recent dynamics of the river Ebro in the Galachos Nature Reserve (Zaragoza), Quaternary and Geomorphology 9(3-4): 85-93.

5. Ollero A (1996) Dynamics of meanders and hydro geomorphological risks in Alcalá de Ebro and Cabañas de Ebro (Zaragoza), IV National Geomorphology Meeting, Cuadernos do Laboratorio Xeolóxico de Laxe 21: 431-443. 